\title{
Limit the number of grants per person
}

Sir - In these times of tight funding, it is surprising that some Principal Investigators (PIs) at the US National Institutes of Health $(\mathrm{NIH})$ have seven or more research grants. (In a recent casual search of the NIH database, I found one investigator with 12 grants.) This distribution has not undergone major changes over time (see Nature $363,578 ; 1993)$.

In general, the more grants one has, the more each is worth. Rather than the infrastructure of one grant assisting another, the opposite appears true. The science done in big laboratories may be of good quality but, for every additional grant given to a big laboratory, several independent investigators are given no chance.

In 1996, three investigators had seven research grants, each averaging almost $\$ 900,000$. For the cost of funding these three investigators, almost 80 PIs were unfunded. If NIH were to limit the number of research grants to two per PI, approximately 3,000 new RO1 grants for young investigators could be funded with no change in the NIH budget and without eliminating any currently funded laboratories.

An examination of the Nobel prizes in biology and medicine makes it clear that the work for which the prize was awarded was done while the investigators were not holders of multiple grants. Nobel prizewinners are obviously bright, well funded and have excellent students, but they don't get more Nobel prizes. Can one buy creativity in science? In the competitive field of molecular biology, the average number of NIH grants per cited author (of the top 10) is 2.1. Apparently more NIH funding is associated with less interesting results.

Grant collectors deprive young people of independent research opportunities and also keep them out of academic institutions. If an applicant doesn't have a continuing line of NIH funding, tenure approval is unlikely. Much discussion has been devoted to bringing young investigators, and particularly minorities, into science. But how can a newcomer compete with established scientists with many grants and dozens of students and technicians?

The NIH should examine, by some objective measure, whether channelling vast sums into big laboratories does produce more productivity per dollar than grants to smaller laboratories. If it doesn't, then NIH needs to revise the rules by which grants are awarded. One possibility would be to limit the number of grants per PI. About 1,200 PIs ( 5 per cent of the total grant recipients) would be affected if awards were limited to two per PI.

If limits were placed on the number of grants per PI, the biggest laboratories would get smaller, and more junior faculty would become independent PIs and generate the key ideas that determine the future path of science. Also, on obtaining a maximal number of grants, PIs would be relieved of the demand (self-inflicted and from administrators) for more proposals.

There are obviously many ways to set limits on grant support and none is immune from abuse and error. But we, the research community, should tell NIH, Congress and the American public that we are willing personally to sacrifice funding opportunities to obtain a more equitable distribution. If we are then rewarded with increased funding by Congress, the increase will not be squandered.

Frederick Sachs

Biophysical Sciences,

118 Cary Hall,

State University of New York,

Buffalo, New York 14214, USA

e-mail:sachs@fred.med.buffalo.edu

\section{True to Tony Blair}

Sir - Thank you for your coverage of my appointment as parliamentary private secretary to the science minister, John Battle (Nature 387, 745; 1997). There is, however, one inaccuracy that I hope you will allow me to correct.

I enthusiastically supported Tony Blair in the leadership election three years ago. In fact I nominated him and worked actively in the campaign team to get him elected. There is no truth in your assertion that I declined to vote for him.

Anne Campbell

(Member of Parliament for Cambridge)

Alex Wood Hall,

Norfolk Street,

Cambridge CB1 2LD, UK

\section{Getting ahead of one's self}

Sir - In these days of excitement about the Beppo-SAX identification of X-rays associated with gamma-ray bursts and the subsequent observations of possible optical counterparts, a frantic

atmosphere has grown among astronomers anxious to establish priorities.

I noticed with surprise the Letter by Sahu et al. (Nature 387, 476-478; 1997) which appears to have been received on 31 March and starts by explaining that: "The optical counterpart of GRB970228 was observed with the HST Wide Field and Planetary Camera (WFPC2) on 26 March and 7 April...”.

I doubt that this is a misprint, because a NASA press release (97-63) of 1 April announces that the same authors have submitted a paper to Nature.

I suggest that you publish a correction asking readers to insert in the abovementioned article, after the title, the sentence "Note added in proof".

Giorgio G. C. Palumbo

Department of Astronomy,

University of Bologna,

40126 Bologna, Italy

e-mail:ggcpalumbo@astbo3.bo.astro.it

- The original submission was based only on the Hubble data of $26 \mathrm{March}$. A revised version containing the 7 April Hubble data was the one sent to referees and published. It is Nature's policy in such circumstances to change the received date, but by an oversight we failed to do so on this occasion.

-Editor, Nature.

\section{Capital Letters}

Sir - I write on behalf of 27 scientists in the School of Biological Sciences at Flinders University who have signed this letter.

Despite the widely held view that Letters to Nature present results of exceptionally high scientific achievement and outstanding originality, the Australian federal government's Department of Employment, Education, Training and Youth Affairs has recently decided that Letters to Nature are not an appropriate measure of scientific output for the purposes of determining infrastructure grants to Australian universities ${ }^{1}$.

James Watson and Francis Crick might be interested to learn that they have perhaps been found wanting by modern Canberra bureaucrats. Nature itself may also feel diminished by this decision.

\section{G. P. Findlay}

School of Biological Sciences,

Flinders University,

GPO Box 2100,

Adelaide,

South Australia 5001

e-mail:bigpf@cc.flinders.edu.au

\footnotetext{
1. 1997 Higher Education Financial and Publications Research Data Collection Specifications for Preparing Returns (Dept of Employment, Education, Training and Youth Affairs, Canberra).
} 